\title{
Factors influencing quality of life of older persons in Bangladesh
}

\begin{abstract}
The increasing proportion of older persons is creating problems in many countries. In developing countries, the majority of the older persons live in rural areas without adequate modern facilities, and their quality of life is influenced by various factors. It is important to investigate their quality of life and identify and measure the potential factors. Such investigation will aid the development of policies and practices to improve their quality of life. The aim of this study was to describe quality of life and identify the influencing factors on quality of life of older persons in southern Bangladesh. Data were collected from 280 participants living in two southern districts of Bangladesh. Convenient sampling technique and inclusion criteria were used to select the participants. The study shows that the average quality of life score of participants was moderate. Depression, social support, health services availability, activities of daily living, and sleep problems accounted for the majority of the variance in quality of life.
\end{abstract}

Keywords: influencing factors, quality of life, older person
Volume 3 Issue 2 - 2018

\author{
Mohammad Abbas Uddin,' Pratum \\ Soivong, ${ }^{2}$ Duangruedee Lasuka, ${ }^{3}$ Phanida \\ Juntasopeepun ${ }^{4}$ \\ 'Lecturer, College of Nursing, Sher-E- Bangla Nagar, Dhaka- 1207 , \\ Bangladesh \\ ${ }^{2}$ Assistant Professor, Faculty of Nursing, Chiang Mai University, \\ Chiang Mai 50200, Thailand \\ ${ }^{3}$ Duangruedee Lasuka,Associate Professor, Faculty of Nursing, \\ Chiang Mai University, Chiang Mai 50200, Thailand \\ ${ }^{4}$ Phanida Juntasopeepun, Assistant Professor, Faculty of Nursing, \\ Chiang Mai University, Chiang Mai 50200, Thailand
}

Correspondence: Mohammad Abbas Uddin “Lecturer, College of Nursing, Sher-E- Bangla Nagar, Dhaka- I207, Bangladesh”. Email uabbas9@gmail.com

Received: January 03, 2018 | Published: April 30, 2018

\section{Introduction}

The proportion of older persons aged 60 years and above is increasing dramatically worldwide. By 2030, there will be more older persons than young persons (aged 15 to 24 ). ${ }^{1}$ It is estimated that nearly 8 in 10 older persons will live in developing countries. ${ }^{2}$ In Bangladesh, the proportion of older person was reported as $6.9 \%$ in $2011 .^{3}$ It is estimated that the proportion of older person in Bangladesh will be $20 \%$ by $2051 .{ }^{4}$ In Bangladesh, the majority of people, and the majority of older persons, live in rural areas. ${ }^{3}$ Generally, these areas have fewer and/or inadequate modern living facilities. The increasing number of older persons is a new and pressing issue in Bangladesh. Therefore, it is becoming increasingly important to be concerned about the older persons.

Older persons are at risk of various problems due to reduced physical and psychological functions. They most commonly suffer from various diseases, including cardiovascular diseases, respiratory diseases, gastrointestinal disease, and bone disease. ${ }^{5-6}$

They also face some social problems. ${ }^{7}$ In Bangladesh, policies to support older persons financially have not yet been fully implemented. Therefore, the majority of older persons depend on their own resources and those of family members. Many older persons have limited resources available to them, which affects the proper management of their health and social problems. ${ }^{8}$ This increases their risk of disability and affects their quality of life (QOL).

QOL is defined as "an individual's perception of their position in life in the context of the culture and the value systems in which they live, and in relation to their goals, expectations, standards, and concerns". Studies among older persons in developing countries found that their overall QOL score was moderate. ${ }^{10}$ The QOL score was low among the older persons in the northern districts of Bangladesh ${ }^{5}$ and moderate in southern districts of Bangladesh. ${ }^{11}$ These studies also found some demographic factors linked to the QOL, including economic status, family structure, and gender. Several studies in other countries showed that older persons' QOL was significantly influenced by depression, ${ }^{12}$ activities of daily living (ADL), ${ }^{13}$ social support, ${ }^{14}$ health services availability (HAS), ${ }^{15}$ and religiosity. ${ }^{16}$ However, little is known about the factors that influence rural older persons' QOL specifically in Bangladesh.

In this country, the majority of rural older persons are Muslim. Generally, they have high levels of religiosity; ${ }^{17}$ suffer from economic crises and chronic diseases, ${ }^{11}$ sleep problems, ${ }^{18}$ depression; $;{ }^{19}$ and have limited access to health services. ${ }^{20}$ Culturally, families have always taken care of their older persons. However, this traditional system is weakening. Social interactions are decreasing due to the prevalent family structure transitioning from extended to nuclear, the migration of employable sons of the older persons, and changing social norms. ${ }^{8}$ These problems can decrease older persons' QOL.

It has been established that these older persons face significant problems supporting themselves, and there is a genuine need to investigate these issues further. It is envisioned that this research will support future initiatives to improve older person's QOL in Bangladesh.

\section{Materials and methods}

This was a descriptive and predictive design study targeting rural older persons aged between 60 and 75 years who were able to communicate verbally, and free from any cognitive impairment or serious illness. The use of 280 participants was calculated by factoring 40 subjects per predictor. This study used six influential variables and one dependent variable. The participants were recruited from 10 villages in two southern districts. Data collection permission was obtained from an appropriate district level health authority and from the participants. The author obtained the required approval from the instruments' developers via email. Data was collected in September 2015 and January 2016 using a nine-part self-report questionnaire. 
The first part was the cognitive screener, the second part identified demographic characteristics, and the remaining seven parts were the instruments described below.

Seven instruments were used to measure the study variables. All English language instruments were translated into Bengali language using back translation methods. The instruments' reliability was confirmed to be acceptable. However, the Health Services Availability Questionnaire's reliability was unconfirmed because it only had three items

\section{Cognitive screener}

A six-item screener was used to assess older person's cognitive functioning. ${ }^{21}$ This screener contains 6 questions evaluating temporal orientation (day of the week, month, and year), and three-item recall (apple, table, and car). The cut-off point chosen for this study was three or more errors during screening. Therefore, a score of 3 or below was considered to indicate cognitive impairment, and a score between 4 and 6 was considered to show no cognitive impairment.

\section{Demographic characteristics}

This was developed by the researcher. It was used to collect information on age, gender, religion, marital status, educational level, occupation, family type, monthly family income, existence of chronic diseases, and medication use.

\section{QOL}

The Bangla version of the WHOQOL-BREF Questionnaire was used to measure QOL. ${ }^{9}$ It consists of 26 items. There are two items about overall QOL and general health, and 24 further items which cover four domains: physical health, psychological health, social relationships, and environmental factors. Each item was assessed on a 5-point Likert scale with scores ranging from 1 to 5 . Higher scores reflected a higher QOL.

\section{Depression}

The Geriatric Depression Scale-10 used was modified from the original GDS. ${ }^{22}$ This scale consists of ten items: (1) feeling satisfied with life, (2) reduction of activities, (3) feeling empty, (4) being afraid of bad things, (5) feeling happy, (6) feeling helpless, (7) memory problems, (8) feeling full of energy, (9) feeling hopeless, and (10) judgment. Each item's score was either 0 (no depression) or 1 (depression).

\section{ADL}

The Barthel Index was used to measure 10 ADL. ${ }^{23}$ These are (1) bowels, (2) bladder control, (3) grooming, (4) toileting, (5) feeding, (6) transfer, (7) mobility, (8) dressing, (9) stair climbing, and (10) bathing. Total possible scores were between 0 and 20, with lower scores indicating greater functional dependence and higher scores indicating greater functional independence.

\section{Social support}

The Duke-UNC Functional Social Support Questionnaire ${ }^{24}$ was used to measure social support. It consists of eight items, each one representing an aspect of social support: (1) care, (2) love and affection, (3) chances to talk about work, (4) personal and family problems, (5) money, (6) going out and doing things with people, (7) getting advice about important things, and (8) receiving help while sick. Each item was scored using a 5-point scale ranging from 1 ("much less than I would like") to 5 ("as much as I would like"). The potential total score range was 8 to 40 . Higher scores reflected higher perceived social support.

\section{HSA}

The Health Services Availability Questionnaire (HSAQ) was developed by the researcher. The items used to measure HSA were: (1) ease of access to health services, (2) satisfaction with access to health services, and (3) benefits from access to health services. The items were scored using use a 4 -point Likert type scale $(0=$ "not at all") to 3 ("very much"). The total potential scores ranged from 0 to 9 , with the highest score corresponding to the greatest level of availability of health services.

\section{Religiosity}

The Strength of Religious Faith $\mathrm{Scale}^{25}$ was used to measure participants' religiosity. This scale includes 11 items in three domains: religious belief, worship, and prayer. Each item was assessed using a five-point Likert scale ranging from 1 (strongly disagree) to 5 (strongly agree). The potential total scores were between 11 and 55 . Higher scores reflect stronger levels of strength of religious faith.

\section{Sleep problems}

The Athens Insomnia Scale- $5^{26}$ was used to measure sleep problems. It consists of five items: (1) sleep induction, (2) awakenings during the night, (3) final awakening, (4) total sleep duration, and (5) sleep quality. Each item was assessed using a three-point Likert type scale, ranging from 0 (no problem at all) to 3 (very serious problem).

This secondary data were analyzed using a statistical program (SPSS 13.0). The demographic characteristics of the study participants were analyzed using frequency and percentage. Stepwise multiple regressions were performed to evaluate standardized regression coefficients, which explained the influence of factors on the QOL.

\section{Results}

The average age of participants was 65.81 years, with 141 $(50.40 \%)$ male and $139(49.60 \%)$ female. All were Muslim. The majority $(80.00 \%)$ were married, and more than half $(53.20 \%)$ lived in a nuclear type family. More than half $(55.00 \%)$ were illiterate. Less than half $(48.90 \%)$ were engaged in household work. Half reported their family monthly income as between 3,001- 10,000 Taka (1 $\mathrm{USD}=80$ Taka). Most (98.60\%) had health problems (Table 1).

The average scores of participants were: QOL (Mean=73.82, $\mathrm{SD}=9.35$ ), depression (Mean=6.92, $\mathrm{SD}=1.98, \mathrm{ADL}$ (Mean=18.78, $\mathrm{SD}=2.10$ ), social support (Mean=27.28, $\mathrm{SD}=5.17$ ), HAS (Mean 2.31, $\mathrm{SD}=.83)$, religiosity $(\mathrm{Mean}=52.51, \mathrm{SD}=52.51)$, and sleep problems (Mean=6.92, $\mathrm{SD}=4.10)$ (Table2).

Testing assumptions of stepwise multiple regressions showed that the correlation coefficients of the independent variables were below 0.50 , so all factors were used in the analysis. The multicollinearity test showed that the tolerance values ranged from .89 to 97 , and VIF ranged from 1.02 to 1.12 , indicating no multicollinearity. Residuals analysis showed that the residual mean was 0 , indicating normality of residuals. The Durbin-Watson value was 1.66 , which was close to 2, indicating non-auto correlation of residuals. 
Factor enter in the stepwise multiple regression analysis was performed. The dependent variable was QOL and independent variables were depression, ADL, social support, HAS, religiosity, and sleep problems. The last and final model showed the regression fit value (F) was $15.161,(\mathrm{p}<.001)$, indicating fitness. The variables showing a statistically significant effect on QOL in this model were depression $(\beta=.41, \mathrm{p}<.001)$, social support $(\beta=.27, \mathrm{p}<.001), \operatorname{HSA}(\beta=.26, \mathrm{p}<.001)$, $\operatorname{ADL}(\beta=.19, \mathrm{p}<.001)$, and sleep problems $(\beta=-.19, \mathrm{p}<.001)$. These variables accounted for $75.70 \%$ of the variance in QOL (Table 3).

Table I Demographic characteristics of the sample $(n=280)$

\begin{tabular}{|c|c|c|}
\hline Characteristics & Frequency & Percentage \\
\hline \multicolumn{3}{|l|}{ Age } \\
\hline $60-65$ years & 162 & 57.90 \\
\hline $66-70$ years & 77 & 27.50 \\
\hline $7 \mid-75$ years & 41 & 14.60 \\
\hline \multicolumn{3}{|l|}{$($ Mean= 65.8I) } \\
\hline \multicolumn{3}{|l|}{ Gender } \\
\hline Male & $|4|$ & 50.40 \\
\hline Female & 139 & 49.60 \\
\hline \multicolumn{3}{|l|}{ Religion } \\
\hline Islam & 280 & 100.00 \\
\hline \multicolumn{3}{|l|}{ Marital status } \\
\hline Married & 224 & 80.00 \\
\hline Widow & 56 & 20.00 \\
\hline \multicolumn{3}{|l|}{ Education level } \\
\hline Illiteracy & 154 & 55.00 \\
\hline Primary & 94 & 33.60 \\
\hline Secondary & 21 & 7.50 \\
\hline Above secondary & 11 & 3.90 \\
\hline \multicolumn{3}{|l|}{ Occupation } \\
\hline Household work & 137 & 48.90 \\
\hline Agriculture & 68 & 24.30 \\
\hline Unemployment & 48 & 17.10 \\
\hline Business & 17 & 6.10 \\
\hline Labor & 10 & 3.60 \\
\hline \multicolumn{3}{|l|}{ Type of family } \\
\hline Nuclear & 149 & 53.20 \\
\hline Extended & $|3|$ & 46.80 \\
\hline \multicolumn{3}{|c|}{ Family monthly income [I USD = 80 Taka $]$} \\
\hline 300 - 3,000 Taka & 114 & 40.70 \\
\hline 3,00I - I0,000 Taka & 140 & 50.00 \\
\hline I0,00I - 20,000 Taka & 26 & 9.30 \\
\hline \multicolumn{3}{|l|}{ Health problem } \\
\hline No & 4 & 1.4 \\
\hline Yes & 276 & 98.6 \\
\hline
\end{tabular}

Table 2 Variables Scores of the Sample $(n=280)$

\begin{tabular}{llll}
\hline Variables & $\begin{array}{l}\text { Potential } \\
\text { Score }\end{array}$ & Mean & $\begin{array}{l}\text { Standard } \\
\text { deviation }\end{array}$ \\
\hline QOL & $26-130$ & 73.82 & 9.35 \\
Depression & $0-10$ & 6.92 & 1.98 \\
ADL & $0-20$ & 18.78 & 2.10 \\
Social Support & $8-40$ & 27.28 & 5.17 \\
HSA & $0-9$ & 2.31 & 0.83 \\
Religiosity & $11-55$ & 52.51 & 52.51 \\
Sleep Problems & $0-15$ & 6.92 & 4.10 \\
\hline
\end{tabular}

Table 3 Factors influencing participants' quality of life $(n=280)$

\begin{tabular}{llll}
\hline Factors & $\boldsymbol{\beta}$ & $\boldsymbol{t}$ & $\boldsymbol{P}$ \\
\hline Depression & -0.408 & -8.64 & $<.00 \mathrm{I}^{* *}$ \\
Social support & 0.269 & $6.65 \mathrm{I}$ & $<.00 \mathrm{I}^{* *}$ \\
Health Services Availability & $0.26 \mathrm{I}$ & 6.329 & $<.00 \mathrm{I}^{* *}$ \\
Activities of Daily Living & .189 & 4.487 & $<.00 \mathrm{I}^{* *}$ \\
Sleep problem & -0.185 & -3.894 & $<.00 \mathrm{I}^{* *}$ \\
\hline
\end{tabular}

$\mathrm{F}=|5| .6|, P<.00| * *, \mathrm{R}^{2}=.573$, Adj $\mathrm{R}^{2}=.565$, Tolerance $=.693-.95 \mathrm{I}, \mathrm{VIF}=\mid .052$ $-1.442, * * P<.01$.

\section{Discussion}

This study attempted to investigate QOL among older persons and the influence that depression, ADL, social support, HSA, religiosity, and sleep problems have on QOL. The average QOL score was moderate, which was higher than the average QOL score among older persons in a northern Bangladeshi district. ${ }^{5}$ The participants in that study reported a low average QOL score. This variation may be because of the differences in the southern and northern older persons' economic status, literacy, age status, and occupational status. Conversely, the present study's QOL score result is consistent with study results from India. ${ }^{10}$

Following the stepwise multiple regression analysis in this study, the final and last model shows that depression, social support, HSA, ADL, and sleep problems have an effect on QOL, accounting for $75.70 \%$ of its variance.

Depression is a mental confusion described by sorrow, defeat of attention or happiness, thoughts of guilt or low self-respect, troubled sleep or hunger, thoughts of fatigue, and reduced concentration. ${ }^{27}$ Depression is a major psychological disorder and is frequently observed among the older persons. They were suffering from depression experience decreased QOL because depression affects all aspects of life through feeling sad, unhappy and isolated, as well as losing interest about life. In this present study, some possible explanations for the older person's depression are illiteracy, nuclear type of family, low family income, and disease conditions. It was shown that depression most significantly and negatively influenced QOL. This result is consistent with the study findings in Italy ${ }^{12}$ and the USA. ${ }^{28}$ Some possible reasons are that depression has negative effects in older persons feeling, thinking, sharing, relationships, sleep, and also individual care. Thus, depression negatively influences QOL. 
Social support is the availability of help from family or friends. Social support leads the older persons to feel a sense of belonging, enhances their physical and psychological health, and helps to correctly alter them for happy living. Social support is useful to turn to in times of need or crisis to give a broader focus and a positive self-image. If the older persons received social support from friends and family members, it contributed to their QOL. In this present study, social support was found the second most significant and positively influential factor on QOL. The result could be due to the social support that the older persons received from their friends and family members. Social support was found to be more influential than in a study of Korean immigrants in the USA. ${ }^{16}$ This difference could be due to variation in the measuring instruments for social support.

The third most influential factor on QOL was HSA. It is the perceptions of the ease of access to health services, satisfaction with access to health services, and benefits from access to health services. These are essential for management of older person's illness and chronic diseases because they are vulnerable for these illness and diseases. This present study showed that HSA significantly and positively influenced QOL. A possible explanation is that the older persons received HSA that contributed to them being able to lead a normal life through treatment and preventing complications of chronic diseases. This positively contributed to QOL. The present study result was found to be more influential than in a study in Iran. ${ }^{15}$ This variation could be due to differences in the two countries' rural health care services.

ADL was the fourth most influential factor on QOL. The older persons need to perform their ADL by themselves or with the help of others. ADL are essential for independent living. The older persons might require help for completing their ADL due to their physical limitations, aging related changes, and also chronic diseases. More physical limitation indicates more functional dependence, which negatively affects QOL. Older persons with functional dependence must require other family members' support to complete their ADL. ${ }^{29}$ These are basic and most important in older person's daily life and most significantly affect QOL. This present study showed that ADL significantly and positively influenced the QOL. A possible reason is that participants' mean age was 65.81 years. So, reasonably they were quite active and less functional dependence, which may be positively contributed in their ADL and QOL. A similar study in the USA found that increased performance of ADL was positively related to older persons health-related QOL. ${ }^{30}$

The last influencing factor was sleep problems. It is defined as an unsatisfactory quantity and/or quality of sleep often experienced by the older persons. Sleep problems include difficulty falling asleep, difficulty staying asleep, or early final wakening. The older persons ageing related changes affect their normal sleep by falling asleep and awakening more often. These situations might be caused by changes in physical and psychological state, as well as environmental conditions. Sleep problems have a significant impact on the older persons QOL. Sleep problems make barriers in older person's alertness, activeness, and daily functions. This study showed that sleep problems was significantly and negatively influenced the older persons QOL. The most probable reason for this is that if older persons experience sleep problems, they feel sleepy in the day time and cannot even concentrate perform daily activities properly. These effects also negatively impact QOL. This result could be supported by a study conducted among older persons in China that found older persons with a higher score in sleep quality had a higher score in health-related quality of life. ${ }^{29}$ Another study found that sleep problems have negative effects on health and quality of life..$^{30-32}$

\section{Conclusion}

Participants in this study reported a moderate level of QOL. The most significant factor on QOL was depression, followed by social support, HSA, ADL, and sleep problems. Based on the study results, there is a need for effective strategies to reduce depression and sleep problems, and to increase social support, ADL, and use of HSA. Effective implementation of these strategies would enhance the QOL for older persons, particularly in Bangladesh and other developing countries.

\section{Acknowledgements}

The authors were pleased to district level health authority for data collection permission. The authors also pleased to the study participants for their kind support.

\section{Conflict of interest}

The author declares no conflict of interest.

\section{References}

1. United nations. International day of older persons. 2017.

2. United nations. World population ageing: Department of economic and social affairs. Population division. 2013.

3. Directorate general of health services (Bangladesh). Health bulletin. Dhaka: Ministry of health and family welfare. 2016.

4. Hafiz RK, Khan TA, Kabir M, et al. Population ageing in Bangladesh and its implication on health care. European Scientific Journal. 2013;9(33):34-47.

5. Khan MN, Mondal MNI, Hoque N, et al. A study on quality of life of elderly population in Bangladesh. American Journal of Health Research. 2014;2(4):152-157.

6. Khaje BY, Payahoo L, Pourghasem B, et al. Assessing the quality of life in elderly people and related factors in Tabriz, Iran. Journal of Caring Sciences. 2014;3(4):257-263.

7. Aging care. What are social issues facing the elderly. 2015.

8. Islam MN, Nath DC. A future journey to the elderly support in Bangladesh. Journal of Anthropology. 2012;2012(2012):1-6.

9. World Health Organization. Programme on mental health. WHOQOL User Manual. 1988.

10. Hameed K, Brahmbhatt DC, Patil KS, et al. Quality of life among the geriatric population in a rural area of Dakshina Kannada, Karnataka, India. Global Journal of Medicine and Public Health. 2014;3(3):1-5.

11. Uddin MA. Quality of life of older persons in rural Bangladesh. American Journal of Applied Psychology. 2017;6(5):106-109.

12. Eva G, Elisa M, Piera B, et al. Quality of life in the third age: A research on risk and protective factors. Procedia-Social and Behavioral Sciences. 2015;187:217-222.

13. Fusco O, Ferrini A, Santoro M, et al. Physical function and perceived quality of life in older persons. Aging Clinical and Experimental Research. 2012; 24(1):68-573. 
14. Kang HW, Park M, Wallace JP. The impact of perceived social support, loneliness, and physical activity on quality of life in South Korean older adults. Journal of Sport and Health Science. 2016;1-58.

15. Musai M, Mehrara M, Dasht SPH. Elders quality of life in urban and rura areas. International Journal of Applied Economic Studies. 2014;12:1-14.

16. Park J, Roh J, Yeo Y. Religiosity, social support, and life satisfaction among elderly Korean immigrants. The Gerontologist. 2012;52(5):641649

17. Uddin M A. Religiosity of older people in rural Bangladesh Rehabilitation Sciences. 2017;2(4):82-84.

18. Uddin MA. Sleep problems of older people in Bangladesh. Journal of Mental Disorders and Treatment. 2013;3(1):143.

19. Uddin MA. Depression of older persons in rural Bangladesh. International Journal of Sustainable Development Research. 2017; 3(5):47-49.

20. Uddin MA, Soivong PD. Lasuka D, et al. Factors related to quality of life among older adults in Bangladesh: A cross sectional survey. Nursing and Health Sciences. 2017;19(4):518-524.

21. Callahan CM, Unverzagt FW, Hui SL, et al. Six-item screener to identify cognitive impairment among potential subjects for clinical research Medical Care. 2002; 40(9):771-781.

22. Yesavage JA, Brink TL, Rose TL. et al. Development and validation of a geriatric depression screening scale: A preliminary report. Journal of Psychiatric Research. 1983;17(1):37-49.

23. Mahoney FI, Barthel D. Functional evaluation: The barthel index. Maryland State Medical Journal. 1965;14:56-61.
24. Broadhead WE, Gehlbach SH, DeGruy FV, et al. The duke-unc functional social support questionnaire: measurement of social support in family medicine patients. Medical Care. 1988;26(7):709-23.

25. Achour M, Grine F, Mohd Nor MR, et al. Measuring religiosity and its effects on personal well-being: A case study of Muslim female academicians in Malaysia. Journal of Religion and Health. 2014;54(4):984-997.

26. Soldatos CR, Dikeos DG, Paparrigopoulos TJ. Athens Insomnia Scale: Validation of an instrument based on ICD-10 criteria. Journal of Psychosomatic Research. 2000;48(6):555-60.

27. World Health Organization. Mental disorders. 2014

28. Chaichanawirote U. Quality of life of older adults: The influence of internal and external factors (Doctoral dissertation). 2011.

29. Oliveira AMS, Pedreira LC. Being elderly with functional dependence andtheir family caregivers. Acta Paul Enferm. 2012;25(1): 143-149.

30. Baernholdt M, Hinton I, Yan G, et al. Factors associated with quality of life in older adults in the United States. Ouality of Life Research. 2012;21(3):527-34.

31. Lo CM, Lee PH. Prevalence and impacts of poor sleep on quality of life and associated factors of good sleepers in a sample of older Chinese adults. Health and Quality of Life Outcomes. 2012;18(10):72.

32. Khan H, Alessi CA. Sleep and quality of life in older people. In: JC Verster, et al. editor. Sleep and quality of life in clinical medicine. 2008:131-138 